\title{
THE EFFECT OF EXCHANGE TRADING OF GOLD OPTIONS ON THE VOLATILITY OF THE UNDERLYING ASSEI
}

\author{
Adrian E. TSCHOEGL* \\ University of Michigan, Ann Arbor, MI 48109, USA
}

Received 12 November 1981

On April 2, 1981 the European Options Exchange introduced options on gold. Data for the period immediately before and after is consistent with the effect being to reduce the daily price volatility of the underlying asset.

\section{Introduction}

On April 2, 1981, the European Options Exchange in Amsterdam introduced trading in put and call options on gold. This provides an opportunity to investigate the effect of organized option trading on the variance of the price of the underlying asset when this is a commodity.

The issue is of some topical concern. The Commodity Futures Trading Commission has just approved a set of rules that could allow the resumption of commodity options trading, dormant since 1978 when the U.S. Congress ordered curbs intended to stop fraud [Apcar (1981)].

There is very little theoretical or empirical work available on the valuation of commodity options. One exception is Hoag (1978). All the empirical work on the effect of the introduction of exchange trading of options has been with reference to U.S. stocks.

Black (1976) argues that options trading will have little direct impact on the underlying stocks. Hayes and Tennenbaum (1979) investigated the effect of listing on the Chicago Board Options Exchange. They found that option trading decreased the price volatility of the common shares and increased the trading volume. Trennepohl and Dukes (1979) had

* I would like to thank Sang-Rim Choi for his excellent research assistance and Mr. Bill Kokontis of the Statistical Department of the Chicago Mercantile Exchange for providing the data. 
similar results for their volatility study. Branch and Finnerty (1981) found that initial option listings tended to have a positive impact on the prices and trading volumes of the underlying stocks. They did not investigate volatility effects. Whiteside et al. (1981) found that the announcement of options listing gave no evidence of any predictable change in price performance.

Branch and Finnerty (1981, p. 2) argue that any overall favorable price effect is probably due to a listing related increase in the attention, flexibility or trading depth and liquidity of the market for the underlying stock (i.e., increased marketability). However, it is hard to see how these factors could have much effect in the case of gold which already trades almost continuously around the world and does not suffer from any lack of attention. There is an additional reason why one might expect not to see any effect. Two companies, Mocatta Metals, and White, Wcld have been selling and making a market in gold options for a number of years. The introduction of exchange trading therefore does not represent as much of a change as it might.

In the next section we discuss the data and methodology we use to test for the presence of an effect and present the results. The final section is a conclusion.

\section{Data and methodology}

The data consists of the Open, High, Low, Close, and afternoon fixing (PM) prices for gold in London from December 31, 1980 to June 30 , 1981. Gold trades in U.S. dollars and hence there is no exchange rate adjustment. The period provides us with three months of data on either side of the initiation of exchange trading. We use two tests. The first is the ratio of the variance estimates for the ten days before and after April 2nd. The second test is a regression of an estimate of the daily volatility on variables for several potential contributory factors.

The measure of daily volatility is one developed by Garman and Klass (1980). The formula is

$\hat{\boldsymbol{o}}^{2}=0.5(\ln H i g h-\ln \text { Low })^{2}-(2 \ln 2-1)(\ln \text { Close }-\ln \text { Open })^{2}$.

The first test is

$\Omega=\sum_{k=1}^{10} \hat{\sigma}_{t-k}^{2} / \sum_{k=1}^{10} \hat{\sigma}_{t+k}^{2}=\frac{0.262}{0.147}=1.779$. 
Since we do not know what the distribution of our test statistic $\Omega$ is (it is certainly not $F$ ) we have developed an empirical distribution based on 200 20-day samples drawn randomly from the period July 1978 to February 1981. The results indicate that one obtains values of $\Omega$ greater than 1.779 in $22.5 \%$ of the draws.

For the second test we model daily volatility as a function of day-ofthe-week effects [Christie (1981) and Ball et al. (1981)], the afternoon fixing price, an autoregressive term, and a dummy variable which takes on a value of 1 for April 2 to June 30, and 0 otherwise. Regressions not reported here indicated that the days of the week other than Monday were not statistically significant at any reasonable level. The model is

$\hat{\sigma}_{t}=\alpha+\beta_{1}$ Mon $_{t}+\beta_{2} \ln P M_{t}+\beta_{3} \sigma_{t-1}+\beta_{4} D_{t}+\epsilon_{t}$,

where the variables are as described, and $\epsilon_{t}$ is assumed i.i.d. as $N\left(0, \sigma_{\epsilon}^{2}\right)$. The results are (with $t$-statistics in parentheses)

$$
\begin{gathered}
\hat{\sigma}=\begin{array}{c}
0.53+0.02 \text { Mon }-0.07 \ln P M+0.15 \hat{\sigma}_{\mathrm{t}-1}-0.04 D+\epsilon, \\
(1.11)(1.97) \quad(-0.89)
\end{array} \\
R^{2}=0.19, \quad F(4 / 115)=6.81, \quad S E=0.05, \quad N=119 .
\end{gathered}
$$

The only variable significant at the $5 \%$ level or better is the dummy for the existence of exchange trading.

\section{Conclusion}

The results of the two tests are consistent with those of the studies cited above for stocks, and with a hypothesis that the introduction of exchange trading reduces the volatility of the price of the underlying asset. In fact, if one reverses the ratio in the first test, the estimated decline is $44 \%$.

The results may reflect a relationship between volatility and transactions costs. The introduction of an options exchange presumably reduces the cost of trading options. This in turn reduces the cost of introducing information into the market. Telser and Higinbotham (1977) argue that the equilibrium distribution of market clearing prices is asymptotically normal with a standard deviation that varies inversely with the volume of 
trade, giving underlying supply and demand conditions. Thus, other things being equal, the greater volume of trade reduces the total variability by reducing the component duc to the distribution of market clearing prices about the equilibrium price.

\section{References}

Apcar, Leonard M., 1981, CFTC approves trading rules: Dispute with SEC expected to intensify, Wall Street Journal, Sept., 8.

Ball, Clifford A., Walter N. Torous and Adrian E. Tschoegl, 1981, An anomaly to an anomaly: Gold and the 'weekend effect', Unpublished paper (University of Michigan, Ann Arbor, MI).

Black, Fischer, 1976, What happens to stocks when options start trading, Options Newsletter, April 19.

Branch, Ben and Joseph E. Finnerty, 1981, The impact of option listing on the price and volume of the underlying stock, The Financial Review 16, no 2, 1-15.

Christie, Andrew A., 1981, On efficient estimation and intra-week behavior of common stock variances, Unpublished paper (University of Rochester, Rochester, NY).

Hoag, James W., 1978, An introduction to the valuation of commodity options, Working Paper 110 (University of California, Berkeley, CA).

Hayes. Samuel L,, III and Michael E. Tennenbaum, 1979. The impact of listed options on the underlying shares, Financial Management, 72-76.

Garman, Mark B. and Michael J. Klass, 1980, On the estimation of security price volatilities from historical data, Journal of Business 53, no. 1, 67-78

Telser, L.G. and H.N. Higinbotham, 1977, Organized futures markets: Costs and benefits, Journal of Political Economy 85, no. 5, 969-1000.

Trennepohl, Gary L. and William P. Dukes, 1979, CBOE options and stock volatility, Review of Business ard Economic Research 14, no. 3, 49-60.

Whiteside, Mary, William P. Dukes and Patrick Dunne, 1981, Announcement impact on securities of future option trading, Nebraska Journal of Economics and Business 20, no. $2,63-72$. 